\title{
Retinal Terminals in the Goldfish Optic Tectum: Identification and Characterization
}

MARK J. AIRHART AND RICHARD M. KRIEBEL

Division of Biological Sciences, University of Michigan, Ann Arbor, Michigan 48109

(M.J.A.) and Department of Anatomy and Neurobiology, University of Vermont College of Medicine, Burlington, Vermont 05405 (M.J.A., R.M.K.)

\begin{abstract}
Retinal terminal profiles in the goldfish optic tectum were identified electron microscopically after (1) labeling with horseradish peroxidase and (2) in the early stages of degeneration in short-term eye enucleates. All labeled terminals shared certain common morphological characteristics which were identical to those of a population of terminals in normal tecta. Terminals of this type disappeared 30 days after enucleation of the contralateral eye.

Retinal terminal presynaptic profiles were characterized by (1) round and oval synaptic vesicles; (2) mitochondria with irregular, randomly oriented cristae, large intracristal spaces, dilated membrane spaces, and primarily light matrices; (3) a wide range in profile area, $0.06-6.82 \mu \mathrm{m}^{2}$; (4) large numbers of synaptic vesicles per profile area (168 \pm 33 synaptic vesicles per $\mu \mathrm{m}^{2}$; (5) asymmetric synapses; and (6) multiple synaptic contacts $(1.46 \pm$ 0.73 per terminal profile). The postsynaptic elements included both dendritic and, less commonly, pleomorphic vesicle-containing profiles. The majority of postsynaptic dendritic profiles were small $\left(0.01-0.40 \mu \mathrm{m}^{2}\right)$. Serial synaptic contacts were occasionally seen.

The combination of vesicular and mitochondrial morphology ( 1 and 2 above) was necessary and sufficient to establish the retinal origin of a terminal, but use of such criteria would underestimate the number of retinotectal terminals by omitting those which did not have a mitochondrion in the plane of section. The number of such terminals was calculated from independent measurements, and the total number of retinal terminal profiles per area of neuropil was estimated.
\end{abstract}

Key words: visual system, terminal morphology, identified synapses, HRP, degeneration

The goldfish retinotectal pathway has been used extensively in the study of nerve regeneration and axonal specificity (Attardi and Sperry, '63; Jacobson and Gaze, '65; for review see Edds, '79). It is surprising to note that, in such an important experimental system, little is known about the specific morphology and synaptic organization of the retinotectal terminals. Two electron microscopic studies on the teleost Carassius carassius have focused on the general ultrastructure of the tectum and the stratification of its afferents (Ito, '71; Marotte and Mark, '75), but no attempts were made to describe the morphology of retinotectal terminals. An investigation by Meek ('81a,b), on the goldfish, Carassius auratus, has described some of the cell types postsynaptic to retinotectal terminals. These terminals were identified by morphological characteristics enumerated in an abstract by Airhart and Kriebel (' 80 ). This latter report and another preliminary study on Carassius auratus (Stürmer, '81), as well as studies in two other teleasts ( $E u$ gerres plumeiri: Laufer and Vanegas, '74a,b; Holocentrus rufus: Ito et al., '80), relied solely on electron microscopic

Accepted January 26, 1984.

Dr. Mark J. Airhart's present address is Department of Anatomy, Box 19960 A, Quillen-Dishner College of Medicine, East Tennessee State University, Johnson City, TN 37614. Address reprint requests to him at this address. 
degeneration techniques to describe retinotectal terminals. The concern with such studies is that equivocal conclusions may be drawn about normal terminal morphology from necrotic terminals. A recent investigation by Murray and Edwards ('82) labeled retinotectal terminals in goldfish tec. tum by orthograde transport of HRP. The labeled synaptic terminals, however, were in the early stages of degeneration due to the method of introducing HRP into the optic nerve. The emphasis of this study was concerned with quantifying retinal terminals in the tectum and did not focus on the morphology and synaptology of the labeled terminal.

In this report the collective results of four independent studies were used to identify and characterize retinotectal terminals in the goldfish optic tectum. The ultrastructure of the tectal neuropil was examined (1) in normal fish; (2) after uptake of intravitreally injected horseradish peroxidase (HRP); and (3) in the early and (4) late stages of degeneration induced by eye enucleation. Specifically, these studies were designed to describe the structure and synaptic connections of labeled retinal terminals ( 2 and 3 above), and to determine whether unlabeled retinal terminals could be distinguished from others in the tectal neuropil (1 and 4).

\section{MATERIALS AND METHODS}

Adult goldfish (Carassius auratus), 5-8 cm long, were kept in aerated aquaria on a diurnal light cycle at room temperature, $21-25^{\circ} \mathrm{C}$.

\section{Surgery}

Animals were anesthetized in a $0.02 \%$ aqueous solution of tricaine methane sulfonate (MS-222) and surgery was carried out under a dissecting microscope. The procedure for eye enucleation included cutting the conjunctival membrane surrounding the eye and severing the oculomotor muscles at their insertions. The optic nerve was then transected in the posterior orbit and the eye was removed.

\section{Electron microscopy tissue preparation}

Anesthetized fish were perfused intracardially with 5.0 $\mathrm{ml}$ of $0.7 \%$ saline followed by $2.5 \%$ glutaraldehyde and $2.0 \%$ paraformaldehyde with $3.0 \%$ sucrose in Sorensen's phosphate buffer ( $\mathrm{pH} 6.9 ; 80 \mathrm{mM})$. The brain was exposed by removal of the calvaria and the fish was immersed in the same fixative for 2 hours. Brains were sectioned transversely with a razor blade at a midpoint along the rostrocaudal axis of the optic tectum. From the rostral portion, the two telencephalic lobes were removed and the two rostral half-tecta and underlying brain structures were bisected sagittally. Each rostral half-tectum was further cut into dorsomedial (DM), dorsolateral (DL), and ventrolateral (VL) thirds (Fig. 1). Tissue blocks were washed in phosphate buffer $(\mathrm{pH} 6.9 ; 80 \mathrm{mM})$ and postfixed in phosphate-buffered $2.0 \%$ osmium tetroxide for 30 minutes. After dehydration through a graded series of alcohols, tissue was embedded in Epon. Sections $1 \mu \mathrm{m}$ thick were taken to determine the orientation of the block, and thin sections were cut at 70$80 \mathrm{~nm}$ and mounted on copper grids (200-300 mesh) or Formvar-coated slot grids. Thin sections were stained with aqueous uranyl acetate and lead citrate and viewed in a Philips 300 electron microscope.

\section{Horseradish peroxidase histochemistry}

Retinal axons and terminals were labeled with antero-

\begin{tabular}{ll} 
& \multicolumn{1}{c}{ Abbreviations } \\
nG & Nucleus glomerulosus \\
nRL & Nucleus recessus lateralis \\
OT & Optic tectum \\
SAC & Stratum album centrale \\
SFGS & Stratum fibrosum et griseum superficiale \\
SGC & Stratum griseum centrale \\
SM & Stratum marginale \\
SO & Stratum opticum \\
VCb & Valvule of cerebellum
\end{tabular}

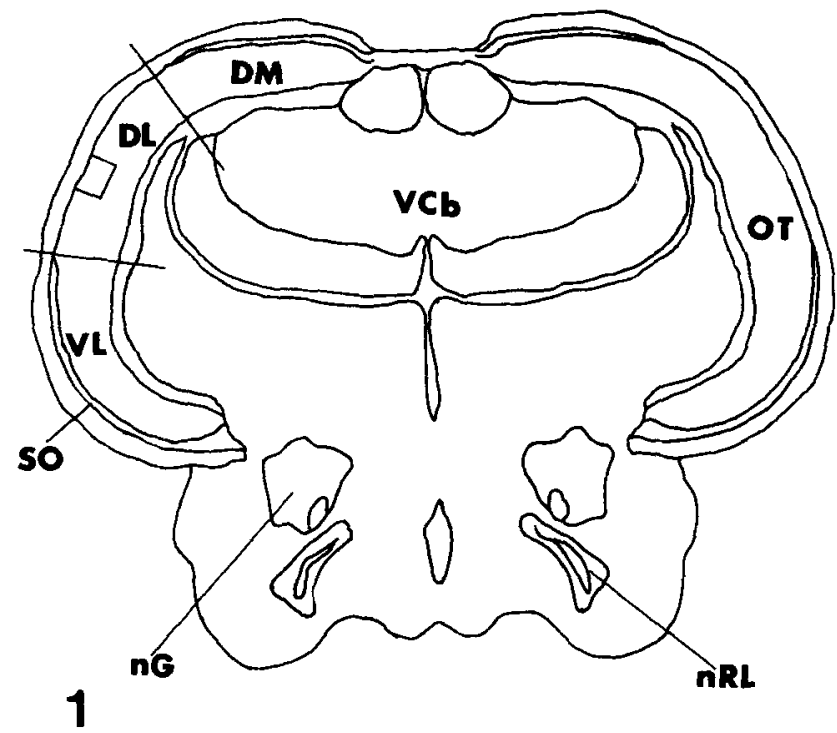

Fig. 1. Schematic transverse section through the midtectal region. For sampling purposes the optic tecta were divided into three sectors: dorsomedial (DM); dorsolateral (DL); ventrolateral (VL). Rectangle indicates site in DL from which electron micrographic photomosaics were taken.

gradely transported horseradish peroxidase (HRP), with diaminobenzidene tetrahydrochloride (DAB) as the chromagen. Ten microliters of $50 \%$ aqueous HRP (Miles) were injected into the vitreous humor of one eye in four fish. Three days later, animals were anesthetized, perfused, and the brains fixed for electron microscopy as described above. The fixed brains were removed from the crania and sectioned transversely with a vibratome at $100 \mu \mathrm{m}$. Sections were collected in phosphate buffer $(\mathrm{pH} 6.9,80 \mathrm{mM})$ at room temperature and washed for a minimum of 2 hours before they were processed according to the methods of Adams (77). Sections were incubated in a $0.05 \%$ solution of $\mathrm{DAB}$, then washed in $80 \mathrm{mM}$ phosphate buffer ( $\mathrm{pH} \mathrm{6.9)}$ and postfixed in $2.0 \%$ osmium tetroxide in phosphate buffer for 30 minutes, dehydrated in $80 \%, 95 \%$, and $100 \%$ ethanol (1 minute each), immersed in propylene oxide, and transferred to a 1:1 mixture of propylene oxide and Epon. Before final embedding with Epon in flat molds the sections were examined by light microscopy to establish approximate rostrocaudal position and to select areas of heavy labeling for further analysis. The coronal sections from rostral, middle, and caudal aspects of the tecta were each divided into three parts, DM, DL, and VL (Fig. 1). Blocks were initially sectioned at $1-2 \mu \mathrm{m}$ to determine the amount and distribution of labeled profiles. The label could be visualized with the light microscope as black punctate grains or black fila- 
ments exhibiting varicosities (Fig. 2). Thin sections were cut at 70-80 nm and mounted on 300-mesh copper grids.

\section{Morphometric analysis of terminal profiles}

Terminals were defined as boutons which formed a minimum of one synapse. Synapses were identified by the presence of paramembranous thickenings and three or more synaptic vesicles adjacent to the presynaptic membrane thickening. The areas of HRP-labeled terminal profiles and associated postsynaptic profiles were measured using a Zeiss MOP-3 image analyzer. Synaptic vesicles were counted in both labeled and unlabeled terminals and expressed as a function of profile area exclusive of mitochondrial area. All synaptic vesicles in a given terminal profile were measured using a calibrated ocular grid at a final magnification of $42,500-47,600 \times$. Mean axis diameter was calculated as the mean of the short and long axes of each synaptic vesicle, and an ellipticity index was calculated as the ratio-long axis:short axis. The synapse length of labeled retinotectal terminals was measured as the linear distance between the furthest points on each end of the postsynaptic membrane thickening. All values are expressed as the mean \pm S.D. unless otherwise stated.

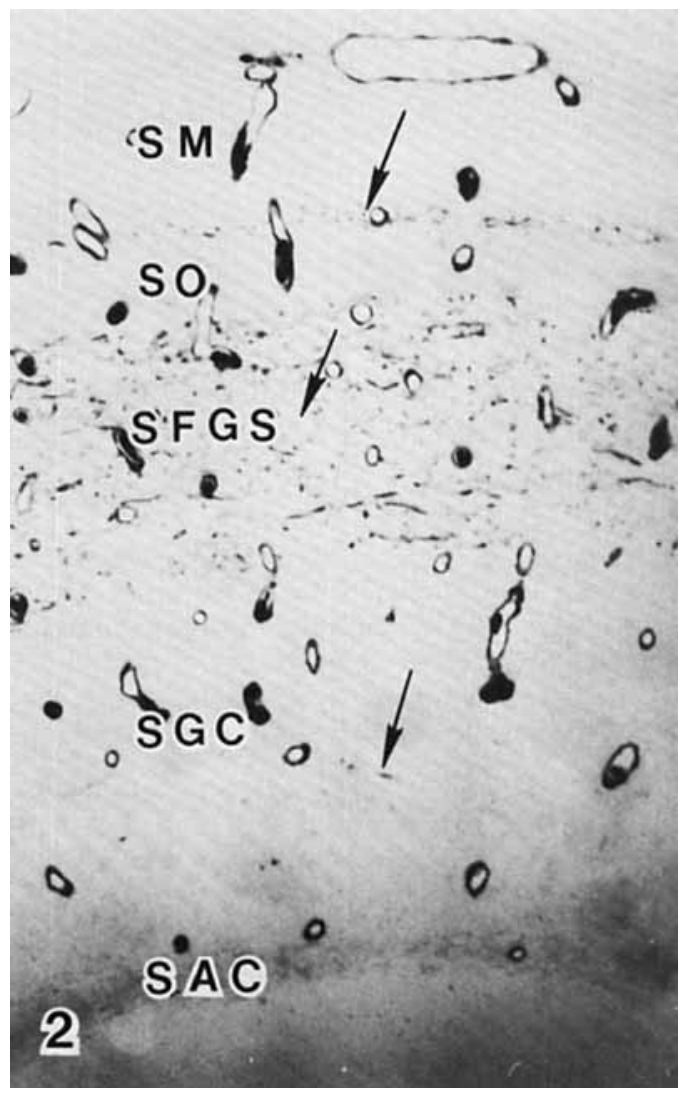

Fig. 2. Photomicrograph of an unstained thick plastic section through VL of optic tectum at approximately the same rostrocaudal level as in Figure 1. Note the distribution of HRP/DAB reaction product in tectal laminae following an intraocular injection of HRP and 3 days survival. Reaction product is observed in a thin lamina above the SO, and in the SO, SFGS, and SGC, arrows. See abbreviations above Figure $1 . \times 190$.

\section{Areal density of morphologically defined terminal profiles}

The density of morphologically defined terminal profiles in the stratum fibrosum et griseum superficiale (SFGS) of normal (unlabeled) tecta was determined from photomosaics. A single photomosaic per tectum was scored for morphologically defined terminal profiles and each class of terminal profile was expressed as an areal density, number of terminal profiles $/ 100 \mu \mathrm{m}^{2}$. The black rectangle in Figure 1 indicates the sample area from which photomosaics were taken and printed at a final magnification of $22,000-24,000 \times$. The entire radial height of the SFGS, however, was not included in the photomosaic because the precise border of the SFGS nearest the tectal ventricle could not always be distinguished accurately at the electron microscopic level. Adjacent thick sections from which the boundaries could be obtained were used to determine the height of the SFGS for each animal. The electron micrographic photomosaics included the superficial 58-60\% of the SFGS.

\section{RESULTS \\ Terminal types in the SFGS}

To determine the morphologically distinct terminal types in the SFGS, both normal and HRP-labeled tecta were examined. All terminals in the SFGS were classified into two categories depending on the shape of their agranular synaptic vesicles. The $R$ terminals contained round and oval synaptic vesicles, and the $P$ terminals contained a pleomorphic mixture of round, ellipsoidal, and flattened vesicles. The $R$ terminals were divided further into three categories according to the presence or absence of mitochondria and mitochondrial morphology.

The $R_{1}$ terminals contained mitochondria characterized by a comparatively large space between inner and outer mitochondrial membrane (membrane space), relatively large intracristal spaces, and irregularly shaped cristae, randomly oriented in a matrix which was usually electron lucent (Figs. 3,4). The $R_{1}$ terminals were variable in size and shape, with irregular and scalloped contours. They were distributed as single profiles or occasionally in clusters of two to five terminal profiles throughout the neuropil. The synaptic vesicles were usually densely packed (151 \pm 27 vesicles $/ \mu \mathrm{m}^{2}, \mathrm{~N}=7$ ) and had a mean diameter of $500 \pm$ $97 \AA(\mathrm{N}=236)$ and an ellipticity index of $1.20 \pm 0.13(\mathrm{~N}=$ 236). Occasionally dense-cored vesicles were observed. The axoplasm was electron dense relative to that of other terminal types in the neuropil, and frequently contained neurofilaments and sometimes microtubules. $R_{I}$ synapses were asymmetric (Gray type 1, Gray, '59), and often profiles were observed with more than one synapse. $R_{1}$ terminal profiles primarily contacted small dendritic profiles and were not observed to synapse on cell somata.

In the $R_{2}$ terminal population, terminal profiles contained mitochondria with two distinct morphologies: (1) mitochondria with small membrane and intracristal spaces and a matrix showing varying degrees of electron density (Fig. 5) and (2) mitochondria with small membrane spaces, small- to normal-sized intracristal spaces, and electrondense matrices (Fig. 3). $\mathbf{R}_{2}$ terminals were rarely found in clusters or with more than one synapse per profile. While these terminals primarily contacted small dendritic profiles, they also synapsed on proximal dendrites and cell somata. $R_{2}$ terminals closely resembled the $R_{1}$ profiles with respect to vesicle size $(480 \pm 64 \AA, N=139)$, vesicle shape 


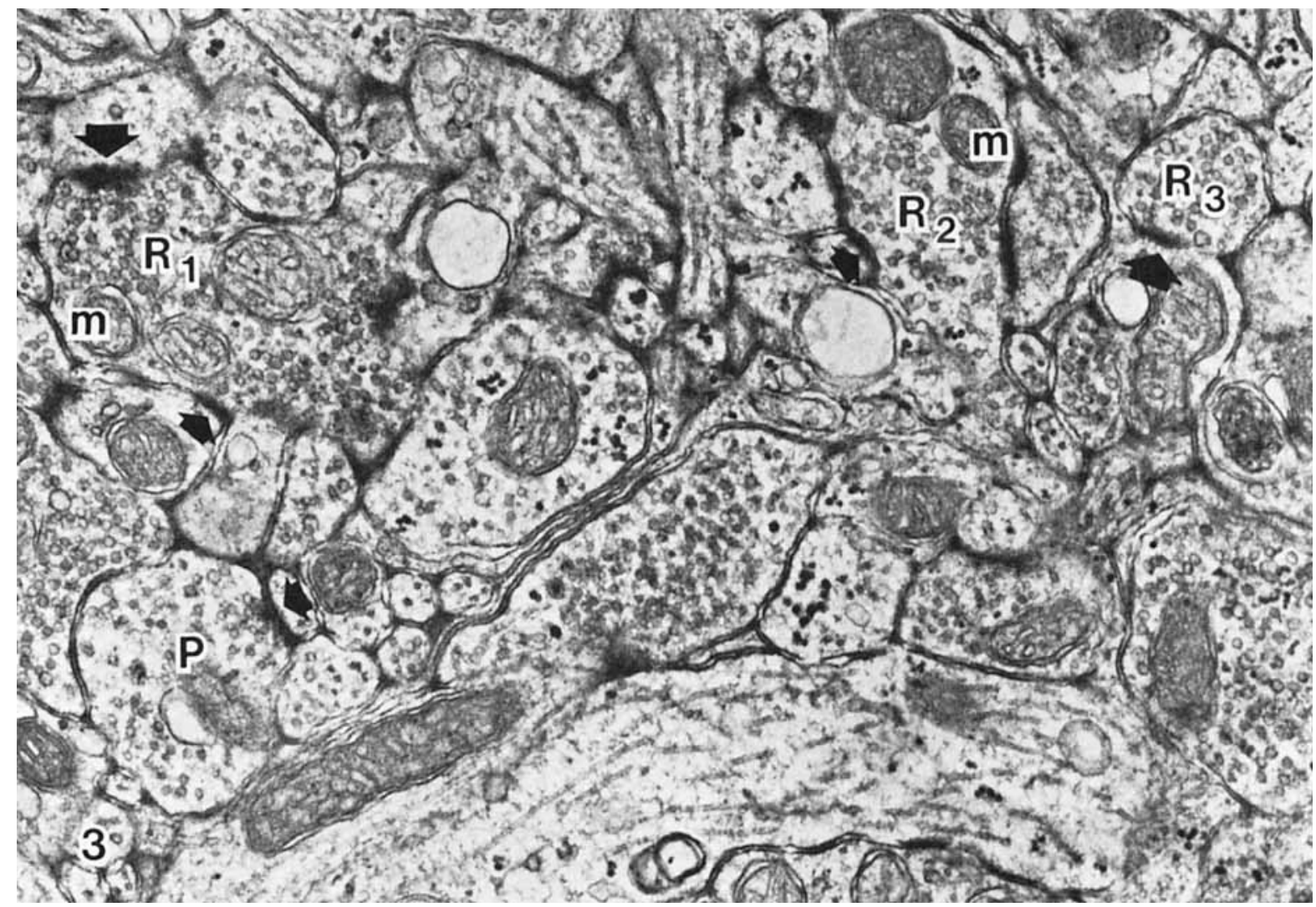

Fig. 3. An electron micrograph of the SFGS showing examples of all four types of morphologically distinct terminals. Note the differences in mitochondrial (m) morphology between $R_{1}$ and $R_{2}$ terminals. Synapses are denoted by arrows. $\times 30,450$.

(ellipticity index $=1.17 \pm 0.17, \mathrm{~N}=139$ ), and asymmetric synapse type. The primary distinction between $R_{1}$ and $R_{2}$ terminals involved the morphology of the mitochondria, particularly that of the membrane space and cristae. There were two other differences that were not consistent enough to serve as identifying characteristics in all of the cases, but which regularly accompanied the mitochondrial criteria. The $R_{2}$ synaptic vesicles were often less numerous ( 124 \pm 40 vesicles $/ \mu \mathrm{m}^{2}, N=8$ ), and the $R_{2}$ axoplasm was often more electron lucent and contained fewer microtubules and neurofilaments.
The $\mathrm{R}_{3}$ terminals had morphological characteristics common to both $R_{1}$ and $R_{2}$ terminals; however, they lacked mitochondrial profiles (Fig. 3 ). $R_{3}$ terminals contained round and oval synaptic vesicles with a wide range of vesicle number per profile area. These terminal profiles had asymmetric synapses and frequently multiple synaptic contacts per terminal. They primarily contacted small dendritic profiles but occasionally synapsed on proximal dendrites and cell somata. From these observations, we suggest that $R_{3}$ terminals result from random sections through $R_{1}$ and $R_{2}$ terminals that excluded mitochondria. The relative density

TABLE 1. Density and Percent of SFGS Terminal Types

\begin{tabular}{|c|c|c|c|c|c|c|c|}
\hline \multirow[b]{2}{*}{ Terminal type } & \multirow[b]{2}{*}{ Mean $( \pm S D)$} & \multicolumn{6}{|c|}{ Arimal No. } \\
\hline & & 1 & 2 & 3 & 4 & 5 & 6 \\
\hline $\begin{array}{l}\text { Total terminal } \\
\text { density }^{2}\end{array}$ & $19.5 \pm 1.8$ & 20.2 & 19.0 & 21.7 & 16.4 & 20.5 & 19.2 \\
\hline $\begin{array}{l}R \text { terminal } \\
\text { density }^{2}\end{array}$ & $7.4 \pm 1.0$ & 6.3 & 8.0 & 8.5 & 6.2 & 7.9 & 8.0 \\
\hline $\begin{array}{l}P_{\text {terminal }} \\
\text { density }^{2}\end{array}$ & $12.0 \pm 1.4$ & 13.9 & 11.0 & 13.2 & 10.2 & 12.6 & 11.2 \\
\hline $\begin{array}{l}R \text { terminal } \\
(\% \text { total })\end{array}$ & $38.0 \pm 4.0$ & 31.0 & 42.0 & 39.0 & 38.0 & 38.0 & 42.0 \\
\hline $\begin{array}{l}\text { P teminal } \\
(\% \text { total })\end{array}$ & $62.0 \pm 4.0$ & 69.0 & 58.0 & 61.0 & 62.0 & 62.0 & 58.0 \\
\hline
\end{tabular}

${ }^{1}$ For description of $\mathbf{R}$ and $\mathbf{P}$ terminals see text.

${ }^{2}$ Density of terminals for each animal was calculated from a single photomosaic and expressed per $100 \mu \mathrm{m}^{2}$. 


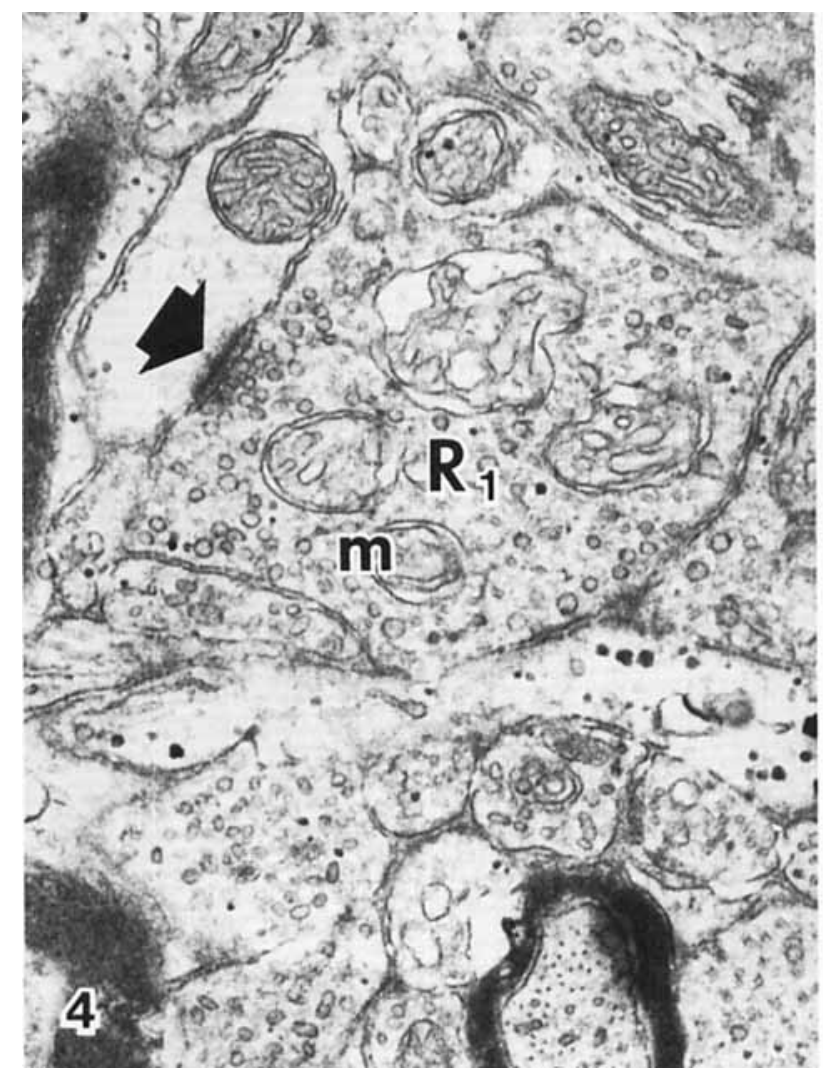

Fig. 4. Electron micrograph showing an $R_{1}$ terminal containing round and oval synaptic vesicles, microtubules, and mitochondria $(m)$ with electron-lucent matrices, large membrane spaces, and randomly oriented irregular cristae with wide intracristal spaces. The terminal exhibits an asymmetric synapse (arrow) contacting a dendritic profile. $\times 45,000$.

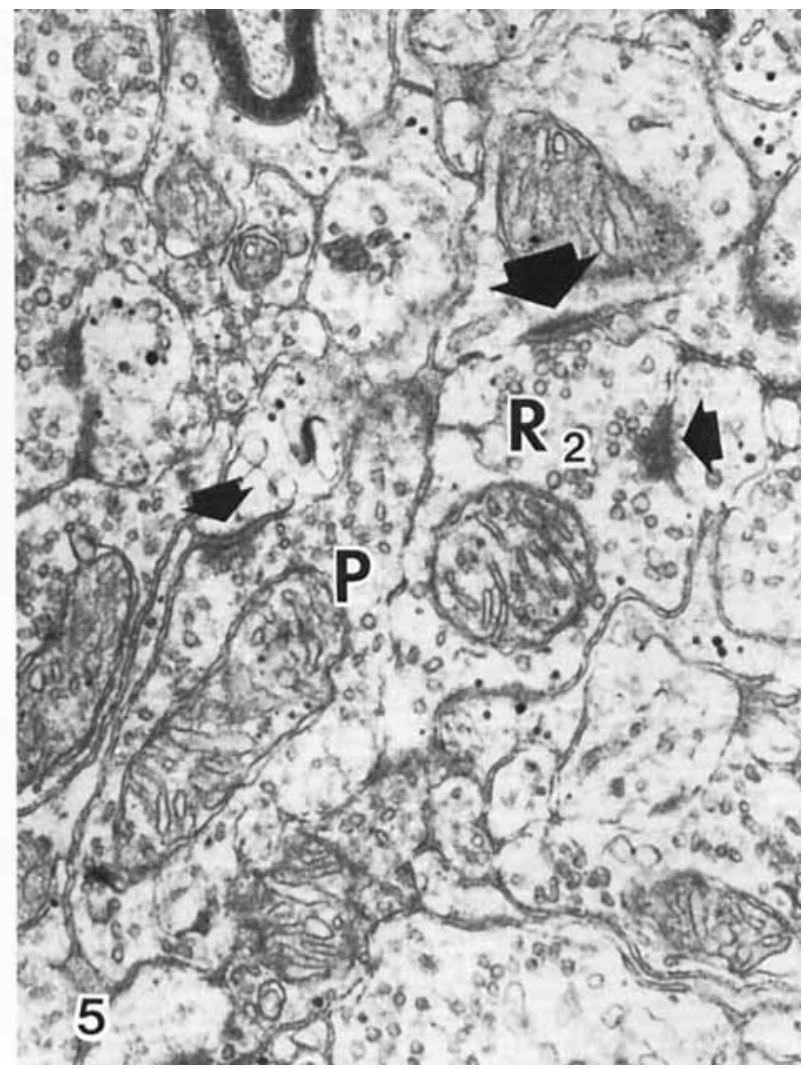

Fig. 5. An $\mathrm{R}_{2}$ terminal making two asymmetric synaptic contacts (arrows) with both large and small dendritic profiles. The $R_{2}$ terminal contains round-to-oval synaptic vesicles and a mitochondrion with small membrane space and cristae having relatively small intracristal spaces. The $P$ terminal, lying just beneath the $R_{2}$ terminal, contains pleomorphic synaptic vesicles (oval to flat in shape) and has a symmetric synapse (arrow) contact ing a dendritic profile. $\times 37,200$.

there were frequently more than one synapse per profile area. $P$ terminals (Fig. 6) synapsed on dendritic elements, cell somata, and occasionally, on profiles with pleomorphic synaptic vesicles. The dendritic elements included profiles as small as dendritic spines $\left(0.01-0.40 \mu \mathrm{m}^{2}\right)$ and as large as proximal dendrites $\left(0.70-1.0 \mu \mathrm{m}^{2}\right)$.

\section{Retinal terminal identification}

Horseradish peroxidase studies. Examination of 1-2- $\mu \mathrm{m}$ thick tectal sections revealed that, 3 days after intravitreal injection of HRP, the contralateral tecta contained HRP/ $D A B$ reaction product in five laminae: the stratum opticum (SO), a thin layer between the SO and stratum marginale (SM), the SFGS, the stratum griseum centrale (SGC), and the stratum album centrale (SAC). Figure 2 shows the typical distribution of label in the upper four laminae of the optic tectum. This projection pattern is consistent with earlier reports of retinal inputs to goldfish tecta using degeneration (Sharma, '72), radioautography (Grafstein, '67; Neale et al., '72; Springer and Landreth, '77), cobalt (Schmidt, '79; Springer and Gaffney, '81), and HRP (Schmidt, '79) procedures. The sparse label in the SO may be due to the mechanism of transport of HRP after intravi-

plasm contained neurofilaments and some microtubules. The synapses of the $\mathbf{P}$ terminals were symmetrical, and 


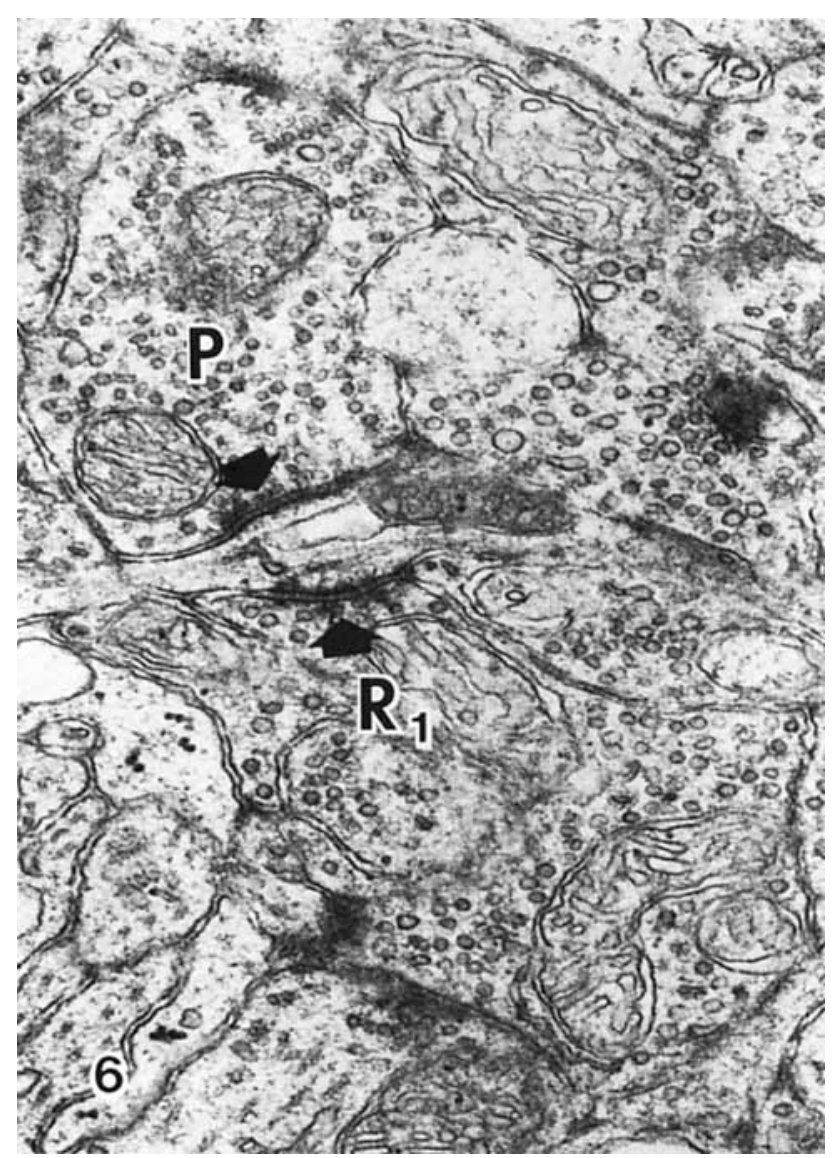

Fig. 6. An electron micrograph of the SFGS showing both a $P$ termina and $R_{1}$ terminal. The $P$ terminal contains pleomorphic synaptic vesicles and forms a symmetric synapse (arrow) contacting a dendritic profile. The dendritic profile is also postsynaptic to an $R_{1}$ terminal (arrow). $\times 40,000$.

treal injection as opposed to injection or implantation of HRP directly into the optic nerve which results in heavy labeling of the SO (Schmidt, '79; Murray and Edwards, '82; Airhart, unpublished observation).

At the electron microscopic level, reaction product homogeneously filled the cytoplasm of certain terminals and axons and made these profiles distinctly darker than others in the neuropil (Figs. 7, 8). The distribution of these profiles paralleled the pattern observed at the light microscopic level since labeled axons were filled in all five laminae including terminals observed in the thin layer just above the SO (Fig. 9), the SFGS (Figs. 7, 8), and the SGC.

The majority of labeled terminals were found in the SFGS. The number varied widely from a low of three to a high of 70 terminals on a given thin section (approximately 15,000 $\mu \mathrm{m}^{2}$ ). The reaction product did not obscure the morphology of the cytoplasmic organelles used in classifying the termi nals (i.e., synaptic vesicles, mitochondria, and synaptic membranes).

The possibility that tissue artifact resulted in nonspecific labeling of terminal profiles was examined. The optic tectum ipsilateral to the injected eye served as a control for endogenous peroxidase activity. Four thin sections from each of four control tecta were examined, and no labeled profiles were observed. The possibility that labeled terminals resulted from a staining artifact was eliminated by examining unstained sections which also contained labeled terminals.

HRP-labeled terminal profiles were evaluated both qualitatively and quantitatively in rostral, middle, and caudal tectal regions of the SFGS. Labeled terminals were photographed in four tecta at a final magnification of 24,000 $28,000 \times$. On a given thin section, all labeled terminals observed were photographed. A total of 164 labeled terminals were photographed; 38 were from rostral, 49 from intermediate, and 78 from caudal tectal sections. An additional 800 labeled terminals were examined at the microscope at a magnification of at least 9,000x. Most of the terminals in the sample came from the VL third of the tectum (Fig. 1) since this was the location of the largest number of labeled terminals.

The ultrastructure of labeled terminals in the SFGS (Figs. 7,8 ) should be compared to the terminal morphology described above for normal tissue (Figs. 3-6). Round and oval synaptic vesicles were present in all 964 labeled terminals. This vesicle morphology strongly suggested that $P$ terminals were nonretinal in origin. Seventy percent of the photographed labeled terminals contained synaptic vesicles and mitochondria. The mitochondria had irregular, randomly oriented cristae, wide intracristal spaces, and in $92 \%$ of the profiles electron-lucent matrices. The mitochondria differed morphologically from those in $\mathrm{R}_{2}$ terminals but were identical to mitochondria in $R_{1}$ terminals. The following morphological descriptors apply to all 164 labeled terminals: Terminals had a wide size range, 0.06-6.82 $\mu \mathrm{m}^{2}$ (Fig. 10) and contained a large number of synaptic vesicles per profile area $\left(167 \pm 33\right.$ vesicles $\left./ \mu \mathrm{m}^{2}\right)$; synapses were asymmetric with a mean length of $194 \pm 57 \mathrm{~nm}(\mathrm{~N}=241)$ and frequently multiple synapses per profile were observed (1.46 \pm 0.73 synapses/terminal profile). Synaptic vesicle size was not measured because reaction product adhered to vesicle membranes. Labeled terminals were also examined qualitatively in the other tectal laminae and were similar to those in the SFGS (see Fig. 9).

Labeled terminals in the SFGS demonstrated a complex network of synaptic connections similar to the $R_{1}$ terminals. These terminals synapsed on both dendritic and vesicle-containing profiles (Fig. 11). Most of the postsynaptic dendritic profiles $(90 \%)$ were small, ranging from 0.01 to $0.40 \mu \mathrm{m}^{2}$, but there was a significant population of larger dendritic profiles ranging in size from 0.41 to $0.90 \mu \mathrm{m}^{2}$ (Fig. 12). Labeled terminals were not observed contacting cell somata and in only one instance was a labeled terminal observed contacting a proximal dendrite. Ten percent of the postsynaptic profiles contained vesicles. These profiles

Fig. 7. A large terminal profile in the SFGS labeled with HRP. Note the morphology of synaptic vesicles, mitochondria, and synapse type resembles the $\mathbf{R}_{1}$ terminals. The retinal terminal makes synaptic contact (arrows) with both small and large dendritic profiles (D). $\times 21,600$.

Fig. 8. HRP-labeled terminal in the SFGS demonstrates that the reac tion product does not obscure cytological detail of the terminal. The terminal contains large numbers of round and oval synaptic vesicles, and two asymmetric synapses (arrows) contacting small dendritic profiles. The mitochondrion $(m)$ has a light matrix and cristae with irregular borders randomly aligned and relatively wide intracristal spaces. $\times 54,300$. 


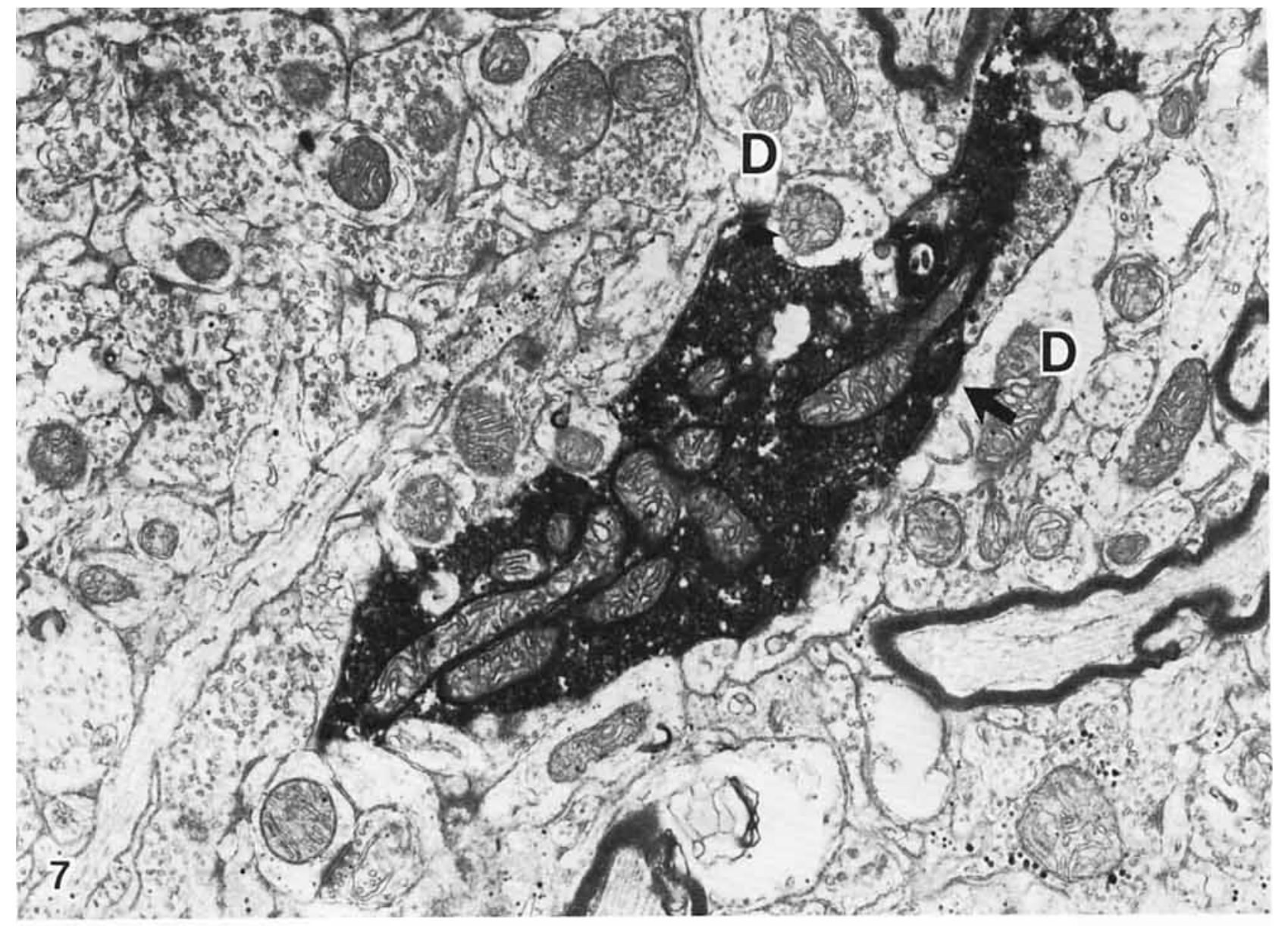

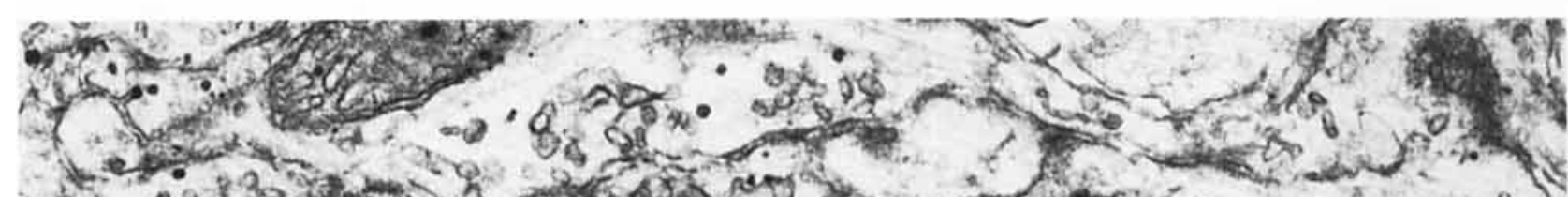

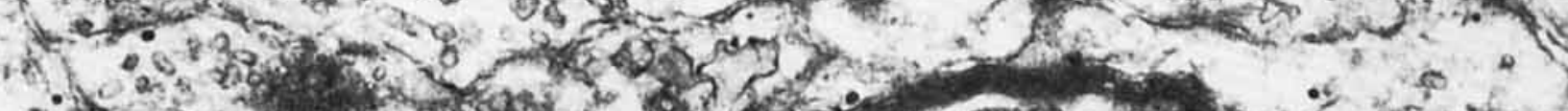

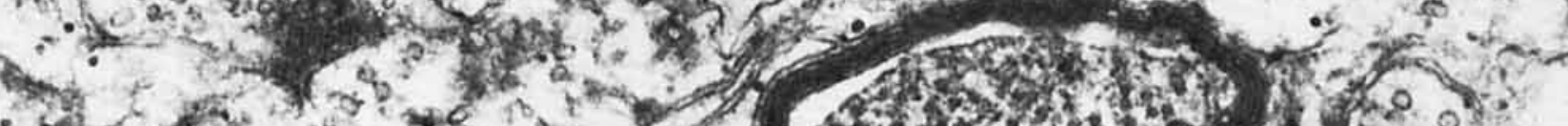

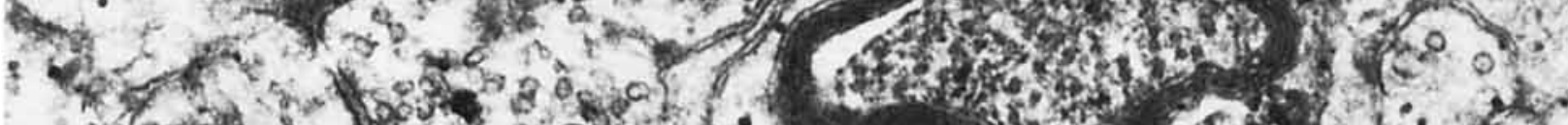

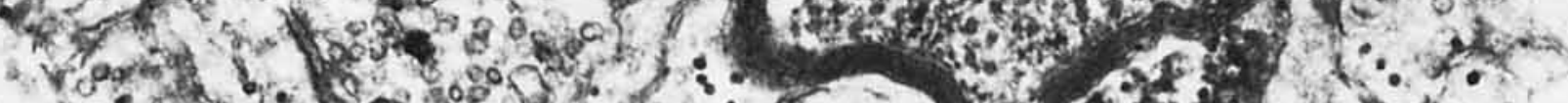

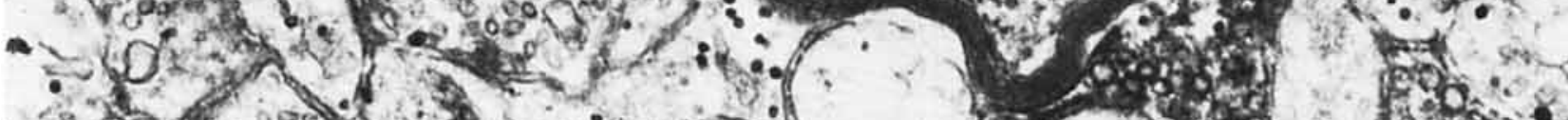

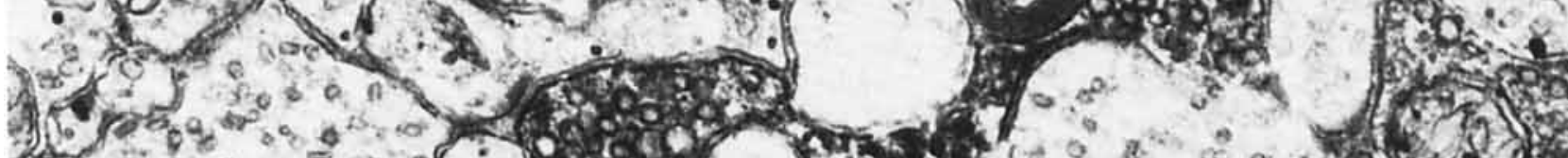

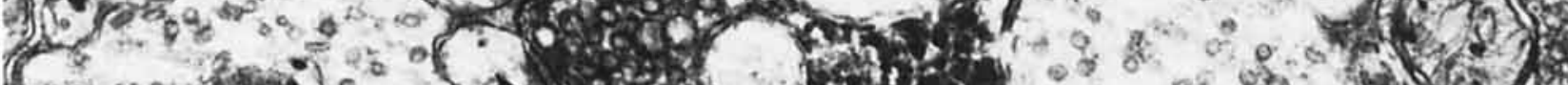

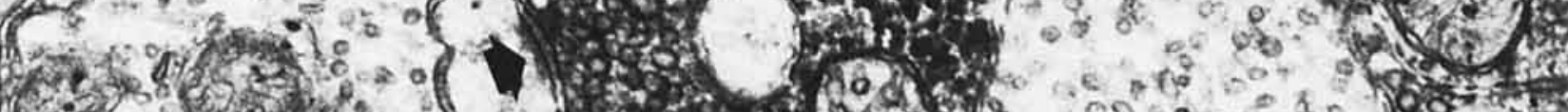

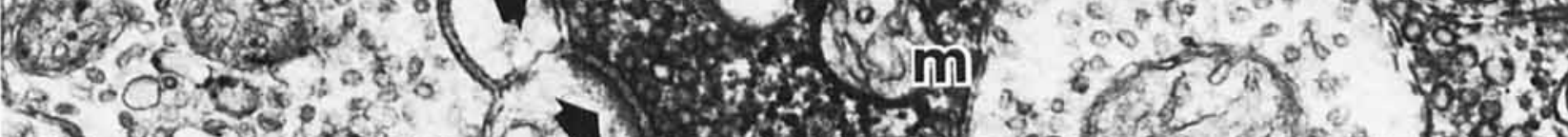
Int io

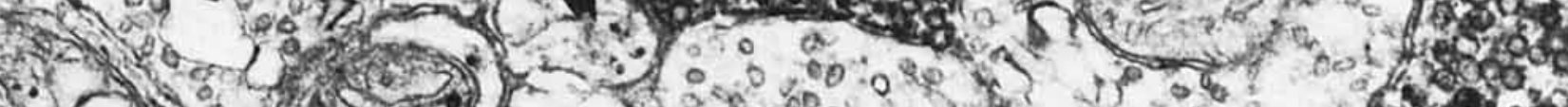

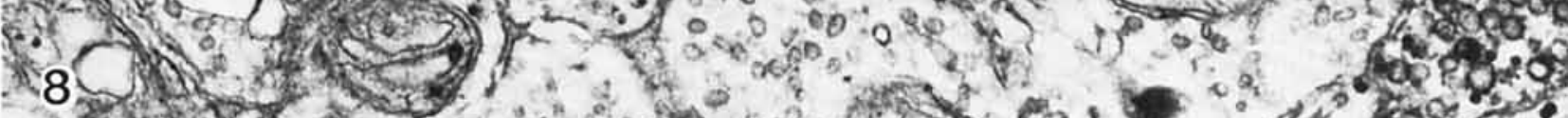

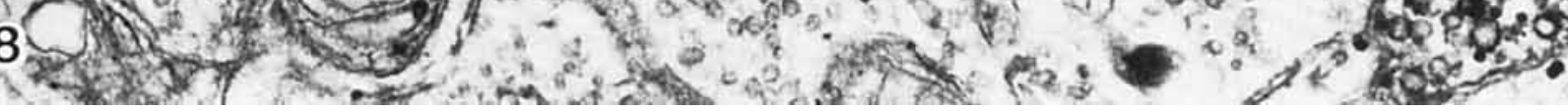




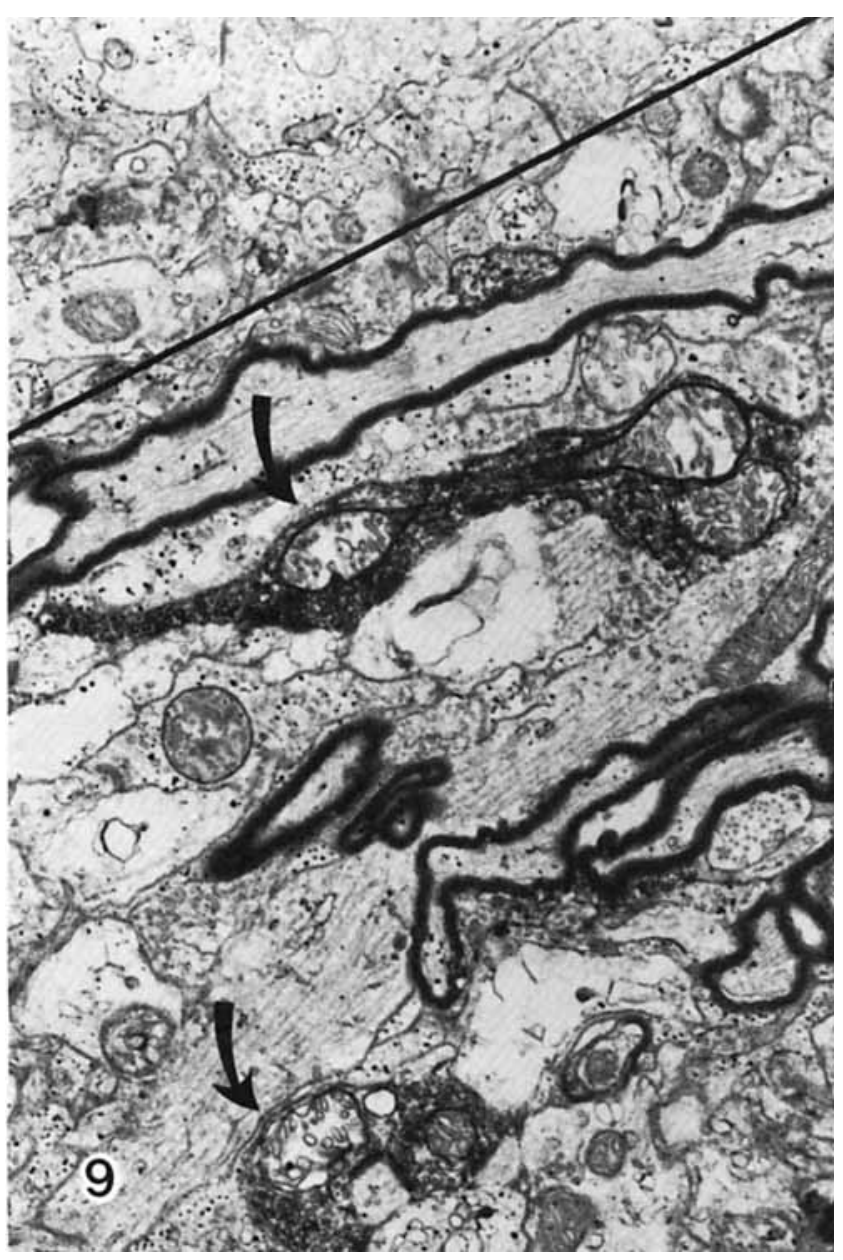

Fig. 9. Labeled retinal terminals (arrows) in the lamina just above the SO, 3 days after intravitreal HRP injection into the contralateral eye. The labeled profiles have the same morphological features as labeled terminais in the SFGS. Black line indicates deepest border of SM. $\times 17,000$.

ranged in size from 0.07 to $0.76 \mu \mathrm{m}^{2}(\mathrm{n}=10)$ and contained pleomorphic synaptic vesicles of the same mean diameter $(450 \pm 63 \AA, \mathrm{N}=104)$ and ellipticity index $(1.47 \pm 0.31, \mathrm{~N}$ $=104$ ) as synaptic vesicles in $P$ terminals. Occasionally, labeled terminals were seen in serial synaptic contacts, i.e., a labeled terminal synapsing on a vesicle-containing profile which, in turn, was in synaptic contact with a small dendritic profile (Fig. 11). Labeled terminals were also observed contacting small dendritic profiles postsynaptic to $\mathrm{P}$ terminals (Fig. 13).

These data show that HRP-labeled retinotectal terminals in the SFGS had morphological characteristics and synaptic connections similar to those of $R_{1}$ and a fraction of $R_{3}$ terminals. If it is assumed that all terminals have mitochondria, then the fact that no $R_{2}$ terminals were labeled leads to the inference that $R_{1}$ and some $R_{3}$ terminals belong to the same population. Therefore, we concluded that at least some of the $R_{1}$ and $R_{3}$ terminals were retinal in origin. This conclusion was further strengthened by the uniform morphological appearance of retinal terminals regardless of their laminar distribution.

\section{Synaptic terminal degeneration studies}

Since the probability that HRP would quantitatively label all retinotectal terminals was low, we felt a second terminal type having pleomorphic synaptic vesicles might have been overlooked. Therefore, we did a correlative electron microscopic degeneration study in the SFGS. While this technique also labels only a portion of the retinal terminal population at any given time, the two approaches are so different in basic mechanism that it is unlikely they would both select against the same terminal type.

Following enucleation of the right eye, the optic tectum was examined ultrastructurally in the midtectal area along the rostrocaudal axis in the dorsolateral region at days 2 (two fish), 3 (two), 5 (two), 11 (one), and 30 (four) postlesion. Degenerating retinotectal terminals were characterized by electron-dense cytoplasm typical of the "dark reaction" described by Heimer and Peters ('68). In the early stages of the dark reaction (Fig. 14), 2-3 days, the number of degenerating terminals varied from 40 to 90 terminals on a given thin section (approximately $15,000 \mu \mathrm{m}^{2}$ ). The retinotectal terminals exhibited varying rates of degeneration. At least half of the early degenerating terminals showed well-preserved ultrastructural features; the morphology of these terminals was qualitatively the same as that described for $R_{1}$ and $R_{3}$ terminals (Figs. 3, 4). Specifically, the degenerating profiles showed round to oval synaptic vesicles; large numbers of synaptic vesicles per terminal profile; mitochon dria with randomly oriented cristae, large intracristal spaces, and primarily light matrices; and asymmetric synapses, often with more than one per profile. Degenerating terminals contacted postsynaptic profiles morphologically similar to those synapsed upon by $\mathrm{R}_{1}$ terminals. Morphological characteristics were not quantified because the terminals were to some degree necrotic.

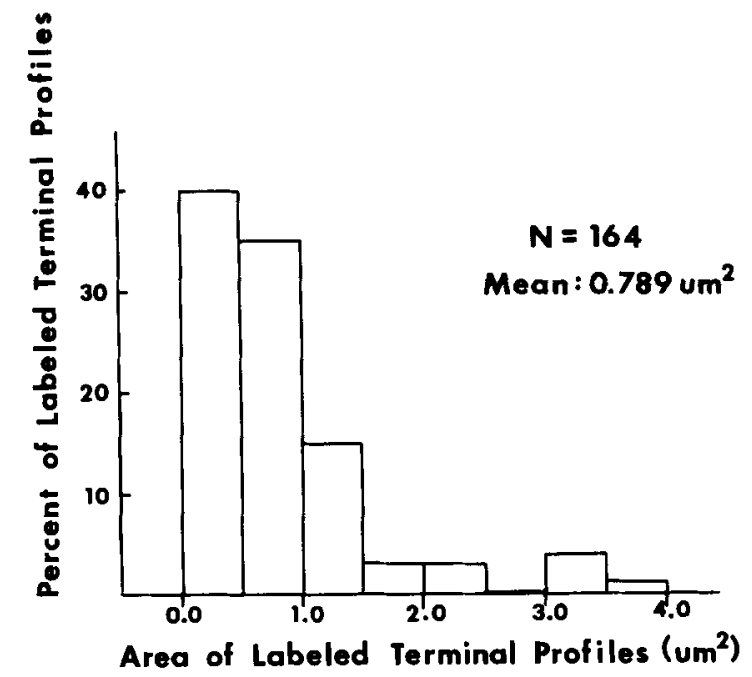

\section{0}

Fig. 10. The area distribution of HRP-labeled retinal profiles in the SFGS. Retinal terminal profiles show a large variation in area ranging from 0.06 to $6.82 \mu \mathrm{m}^{2}(\mathrm{n}=164)$. Ninety percent of the terminals ranged between 0.06 and $1.50 \mu \mathrm{m}^{2}$. 


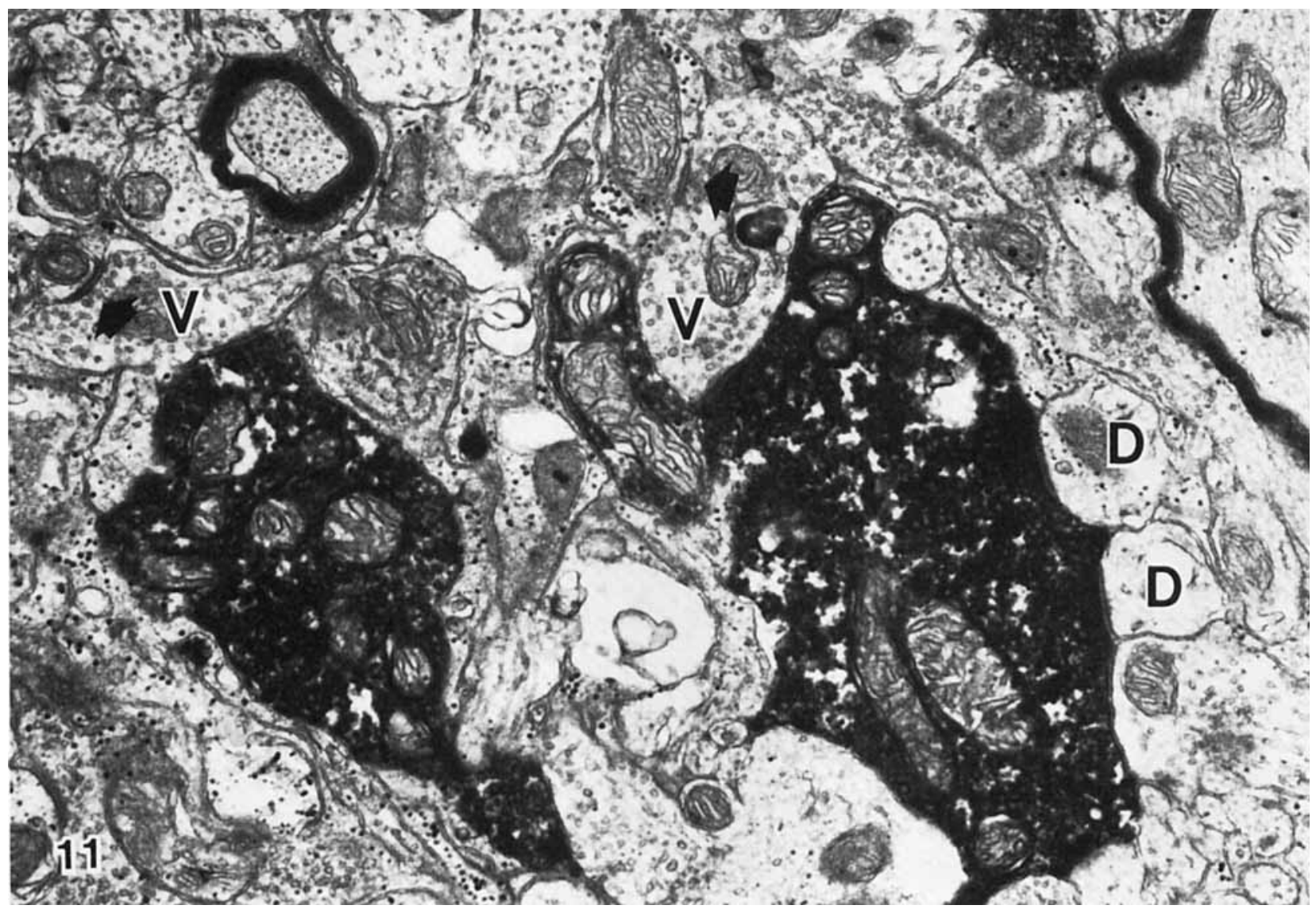

Fig. 11. Two HRP-labeled retinal terminals in the SFGS are making synaptic contact with both dendritic (D) and synaptic vesicle-containing profiles (V). The vesicle-containing profiles (V) also contact small dendritic profiles (arrows) resulting in a serial synaptic arrangement. $\times 29,300$.

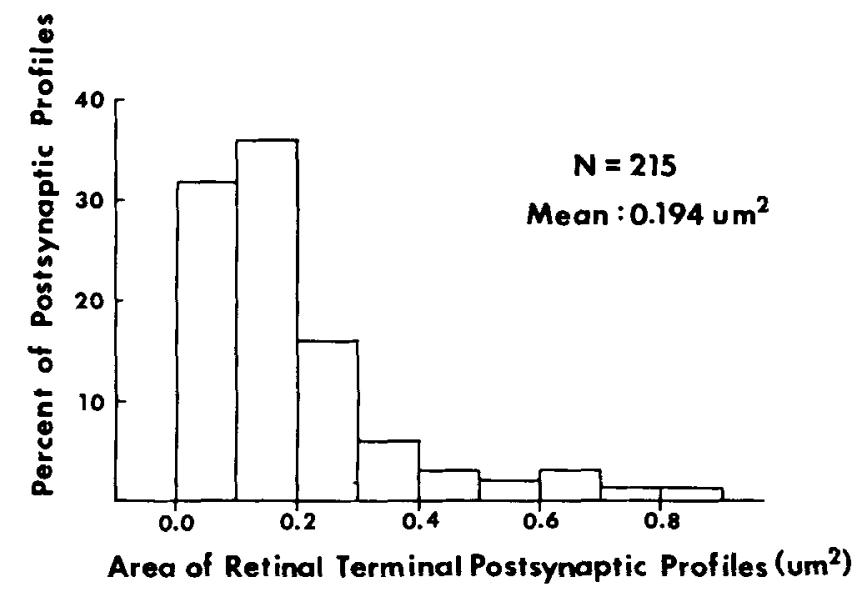

12

Fig. 12. The area distribution of dendritic postsynaptic profiles contacted by labeled retinal terminal profiles. Retinal synapses show a marked pref. erence for a population of small dendritic profiles $\left(0.01-0.40 \mu \mathrm{m}^{2}\right)$ making up 90\% of the measured postsynaptic population.
Those terminals undergoing more rapid degeneration were surrounded to some extent with glial cytoplasm and appeared to be contracted in size. These terminals often contained mitochondria with electron-dense matrices and small intracristal spaces (Fig. 15). We assumed this atypical mitochondrial morphology was due to the degeneration process and not indicative of a second morphological class of retinotectal terminals.

By postenucleation day 5 , there were still a few terminals in the early stages of degeneration, and these showed the same morphological characteristics as $R_{1}$ terminals. However, at this time the number of dark terminals declined, and the majority of the remaining degenerating terminals had contracted in size, and the morphology of their organelles was obscured. At 11 days postenucleation, the few degenerating terminals were surrounded by glial cytoplasm and had lost structural detail. Glial cytoplasm was identified by the following criteria: electron-lucent cytoplasm, presence of glycogen granules, and absence of synaptic contacts. This time sequence of retinal terminal degeneration in the SFGS is in agreement with the findings of Murray ('76).

By 30 days postenucleation there were no degenerating terminals and very few myelinated axons in the SO and SFGS. At this time, approximately $105,000 \mu \mathrm{m}^{2}$ of SFGS neuropil were scanned and no $R_{1}$ terminals were observed 


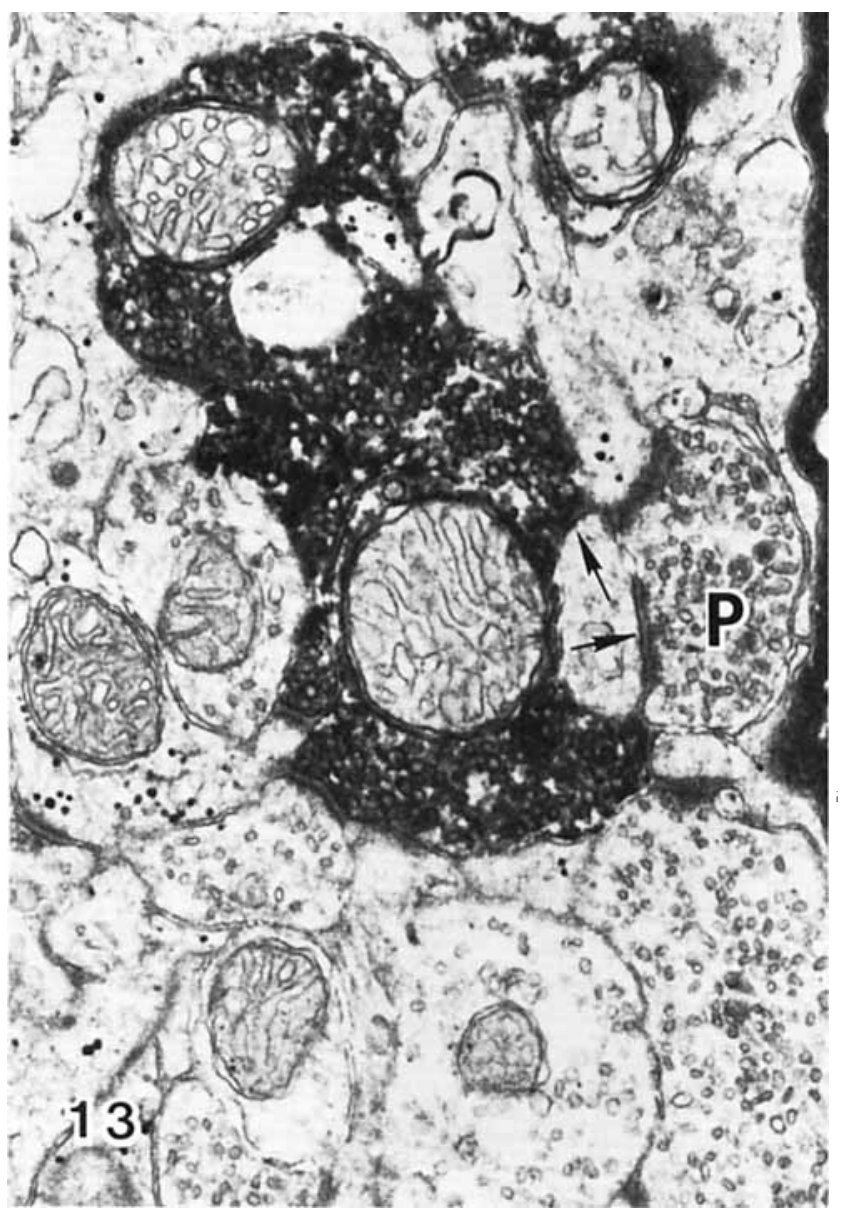

Fig 13. An HRP-labeled retinal terminal in the SFGS synapses on a small dendritic profile (arrow) which also receives a synapse from a $\mathrm{P}$ terminal. $\times 34,200$.

although $R_{2}, R_{3}$, and $P$ terminals were present. The same area in normal tectal neuropil would have contained approximately $3,750 \mathrm{R}_{1}$ terminals (Table 2 ).

These short- and long-term degeneration studies gave further evidence that there was one morphological type of retinotectal terminal, seen in sections as the $R_{I}$ and $R_{3}$ profiles, and that all $R_{1}$ terminals and some $R_{3}$ were of retinal origin. These studies, however, did not exclude the possibility that some $R_{2}$ terminals were of retinal origin, since the variability in mitochondrial morphology seen in degenerating terminals may be only partially due to the consequences of degeneration.

\section{Estimate of retinal terminal area density in the SFGS}

While the morphological distinction between $R_{1}$ and $R_{3}$ terminals was unambiguous, estimation of retinal terminal density required a method for determining what percentage of $R_{3}$ terminal profiles resulted from sectioning $R_{1}$ terminals through planes not including mitochondria. This problem deserves serious attention since $R_{3}$ terminals made up $14 \%$ of the total terminal population and $36 \%$ of the total $R$ terminal population (Table 2). To estimate indirectly the portion of $R_{3}$ terminals that were retinal, the following HRP data were considered: Of $164 \mathrm{HRP}$ labeled retinal terminals, 115 contained mitochondria $\left(R_{1}\right)$ and $49\left(R_{3}\right)$ did not. If this proportion can be generalized for all retinal terminal profiles in the SFGS

$$
\begin{aligned}
& \text { and if } \mathbf{d}\left(\mathrm{R}_{3}\right)=\text { the density of retinal terminal pro- } \\
& \text { and } d\left(R_{1}\right) \quad=\text { the density of retinal terminal pro- } \\
& \text { files with mitochondria (profiles/ } \\
& \mu \mathrm{m}^{2} \text { ), } \\
& \text { then } \mathrm{d}\left(\mathbf{R}_{3}\right)=(49 / 115) \mathrm{d}\left(\mathbf{R}_{1}\right)=0.43 \mathrm{~d}\left(\mathbf{R}_{1}\right) \text {, }
\end{aligned}
$$

or the total areal density of retinal terminal profiles is equal to 1.43 times the density of the $R_{1}$ population. This estimate must be checked against the counts of unlabeled terminals in Table 2. Specifically, are there enough $R_{3}$ terminals to account for the estimated number of retinal origin? There are $131 R_{1}$ terminals and the estimated number of $R_{3}$ profiles of retinal origin would therefore be 0.43 $\times 131=56$. The actual counts showed a total of $95 R_{3}$ terminals. We conclude that the fraction of $R_{3}$ terminals of retinal origin is $56 / 95=0.59$. Thus, the retinal terminal profiles comprised $(131+56) / 263=0.71$ or $71 \%$ of all $R$ terminals. As the $\mathrm{R}$ terminals occurred at a density of 7.4 terminals/100 $\mu \mathrm{m}^{2}$ (Table 1), we estimate an areal density for retinal terminal profiles of $0.71 \times 7.4=5.3$ terminals $100 \mu \mathrm{m}^{2}$ or $5.3 / 19.5=0.27$ or $27 \%$ of the total terminal population of the SFGS.

\section{DISCUSSION \\ HRP labeling of retinotectal terminals}

In addition to the more classical technique of terminal degeneration used to identify retinotectal terminals in other teleosts (Laufer and Vanegas, '74b; Marotte and Mark, '75; Ito et al., '80), the present study also employed anterograde transport of HRP following intraocular injection. We selected an intraocular route of administering HRP rather than the widely used methods of direct injection into the optic nerve or application of HRP to the cut end of the nerve (Robson and Mason, '79; Schmidt, '79; Matsumoto and Scalia, '81; Ingham and Guldner, '81; Murray and Edwards, ' 82 ) because the former procedure allowed visualization of nondegenerating retinotectal terminals. The HRP/DAB-labeled terminals were filled homogeneously with a fine, granular precipitate that made it easy to distinguish labeled and unlabeled terminals. The reaction product in the terminals did not mask the morphology of synaptic vesicles, mitochondria, or synapses. The HRP procedure also added an important degree of confidence to our morphological identification, since it avoided the necessity of examining necrotic tissue inherent in degeneration studies. Obviously, where there is the possibility of damage to cytoplasmic organelles, one can only tentatively relate the morphology of labeled profiles to that of normal terminals.

The density of labeled terminals was not equal in all areas of experimental tecta. All four experimental animals had a higher density of labeled terminals in VL tectum than in either DL or DM tectum. The relatively high density of labeled terminals in VL tectum could not be explained on the basis of HRP transport time, since dorsomedial and ventrolateral brachia are positioned such that retinal terminals in VL tectum are no further from 


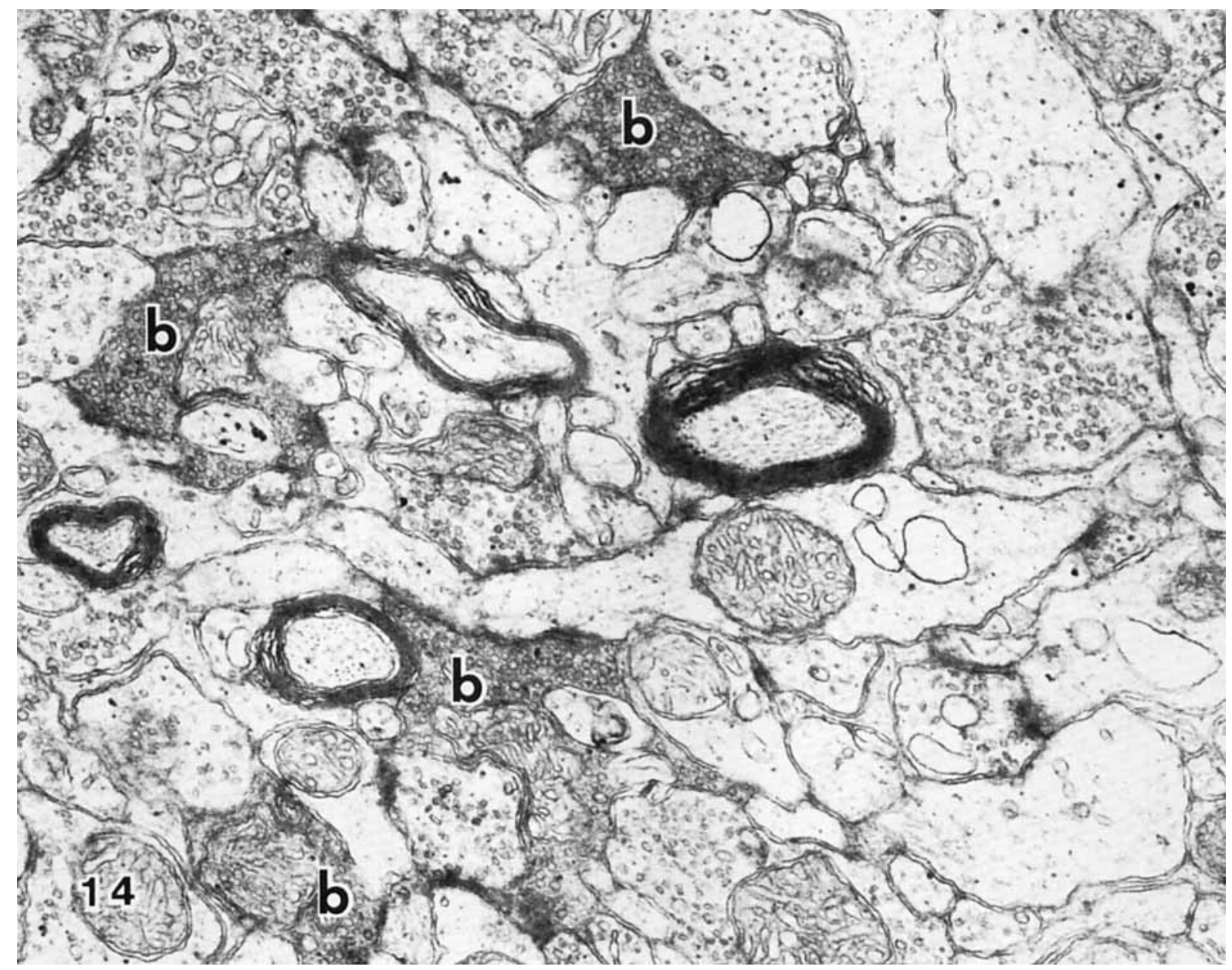

Fig. 14. An electron micrograph of the SFGS from an animal killed 2 days after contralateral eye removal. Note the boutons (b) that show a dark cytoplasm but have not as yet been surrounded by glia. The terminals have large numbers of round and oval synaptic vesicles and mituchondria with light matrices, irregular cristae randomly dispersed, and wide intracristal spaces. The morphological characteristics are similar to the $R_{1}$ terminals. $\times 29,600$ the distal end of the optic tract than retinal terminals in DM tectum. A second possibility was that ganglion cells that projected their axons to VL tectum were damaged by intravitreal injection of HRP. There were two reasons that made that possibility unlikely: (1) Retinal fibers in the SO of VL tectum did not contain $\mathrm{HRP} / \mathrm{DAB}$ reaction product whereas in optic nerve injection or implants of HRP retinal fibers in the SO are always labeled (Schmidt, '79; Matsumoto and Scalia, '81; Murray and Edwards, '82); and (2) the SFGS of VL tectum showed no signs of degeneration as there were no degenerating terminals or fibers and no obvious glial reaction. Therefore, the most likely explanation is that retinal ganglion cells show differences in their ability to incorporate and transport HRP.

\section{Do retinotectal terminals comprise a single morphologic class?}

The combined results of the HRP and degeneration studies showed that all $R_{1}$ and some $R_{3}$ terminals were retinal in origin. The results of these studies, however, did not completely eliminate the possibility that some $R_{2}$ and $P$ terminals were derived from retinal ganglion cells. Although the HRP technique labeled only $R_{1}$ and $R_{3}$ terminals, the possibility remained that HRP was not taken up equally by all types of retinal ganglion cells. Therefore a population of $R_{2}$ and/or $P$ terminals may have gone undetected, because their associated ganglion cells did not take up and transport adequate amounts of HRP.

The degeneration studies lent further support to the observation that all retinotectal terminals contained round to oval synaptic vesicles. The degeneration method, however, is very time dependent and it is conceivable that the degeneration of $\mathrm{P}$ terminals is completely out of synchrony with the degeneration of $\mathrm{R}$ terminals. Although the present study has examined the SFGS of enucleated animals over a long time range, it is still possible that a population of degenerating terminals could have been missed.

Long-term degeneration studies have led to the conclusion that all $R_{1}$ terminals were retinal in origin. This conclusion relied on the assumption that degeneration and subsequent removal of $R_{1}$ terminals was not in part due to transsynaptic degeneration. A study by Murray and Ed- 


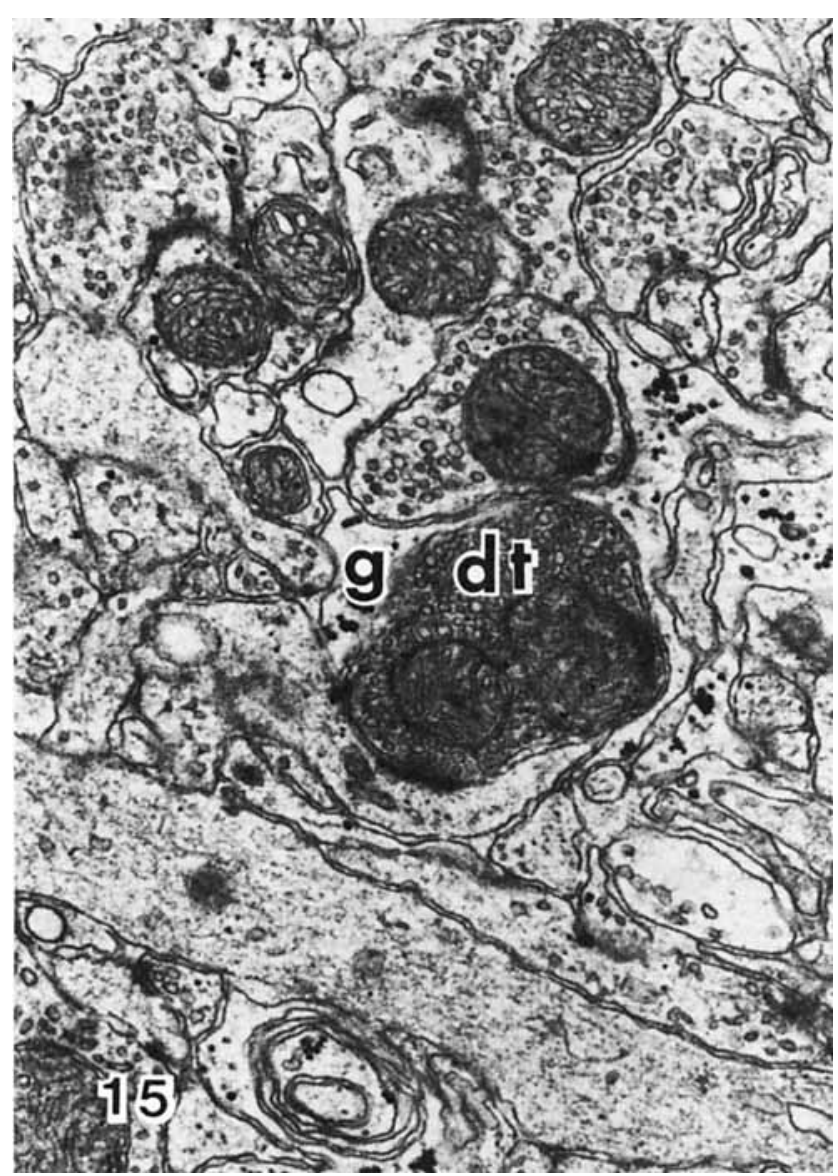

Fig. 15. An electron micrograph of a degenerating retinal terminal (dt) in the SFGS, 5 days after contralateral eye enucleation. The degenerating terminal contains round to-oval synaptic vesicles, mitochondria of atypical morphology, and is surrounded by glial processes (g). $\times 24,000$.

wards ('82) supports this assumption. They estimated the percentage of retinotectal terminals in the SFGS of goldfish tectum using two methods: (1) comparing total terminal density in normal and long-term enucleated animals and (2) determining the maximum density of HRP-labeled terminals subsequent to optic nerve implant of HRP in normal animals. Both methods gave nearly identical answers, $40 \%$ and $37 \%$, respectively, thus supporting the contention that transsynaptic degeneration was not in part responsible for the degeneration of $R_{1}$ terminals.

The collective results of these studies strongly suggest that there is only one morphological type of retinotectal terminals, the $R_{1}$ and a percentage of $R_{3}$ terminals. These conclusions differ to some extent from two previous studies that also examined retinotectal terminal morphology in goldfish tectum (Marotte, '81; Murray and Edwards, '82). Both studies concluded that retinotectal terminals in the SFGS comprised both $R_{1}$ and $R_{2}$ terminal morphologies. These studies, however, exclusively examined degenerating terminals. Marotte examined degenerating retinal terminals 2 days after eye enucleation, and Murray and Edwards observed retinal terminals labeled with HRP and degenerating for 1.5 days. We argue that degenerating retinal ter- minals show a variety of mitochondrial morphologies due to the process of necrosis. Therefore, conclusions about mitochondrial morphology in degenerating terminals can only be tentative.

\section{Comparative aspects of morphologically distinct terminals in the SFGS of teleosts}

Morphologically distinct terminal types in the SFGS have been described in three teleosts: Eugerres plumieri (Laufer and Vanegas, '74a), Holocentrus rufus (Ito et al., '80), and Carassius auratus (Meek, '81a). The terminals in the SFGS of all three genera of teleosts could be distinguished by the shape of their agranular synaptic vesicles and the morphology of their synapses. One class of terminals (R) contained round-to-oval synaptic vesicles and had asymmetric syn apses. The second class of terminal $(\mathrm{P})$ contained pleomorphic synaptic vesicles and symmetric synapses. In all three genera of fish, the $\mathrm{R}$ terminals were divided into at least two subcategories on the basis of mitochondrial morphology. Subclass $1\left(\mathbf{R}_{1}\right)$ contained mitochondria with large intracristal spaces and an electron-lucent matrix. In $H$. rufus these mitochondria were simply described as pale. The second subclass of $R$ terminals $\left(R_{2}\right)$ contained mitochondria that were described somewhat differently in the three fish. In $H$. rufus the mitochondria were described as simply dark. In $E$. plumieri the mitochondria were said to contain regular packed cristae and electron-dense matrices. In $C$. auratus, Meek ('81a,b) described mitochondria in $\mathrm{R}_{2}$ terminals as either having an electron-dense matrix and normal cristae, or as densely filled with narrow cristae leaving little space for matrix. The present study confirms the observations made by Meek on mitochondrial morphology in $\mathrm{R}_{2}$ terminals. All three referenced studies as well as our own use cristae morphology and electron density of the matrix to distinguish between mitochondria in $R_{1}$ and $R_{2}$ terminals. All of these studies agree that mitochondria in $R_{1}$ terminals have larger intracristal spaces and lighter matrices than mitochondria in $R_{2}$ terminals. This analysis demonstrates that in teleosts so far examined the terminal composition of the SFGS is essentially the same.

\section{Comparative aspects of retinotectal terminal morphology and synaptic connections}

The present study gives further support to the hypothesis that there is a strong cytological similarity in retinotectal terminal morphology across vertebrate lines. Among teleosts, retinal terminals of E. plumieri (Laufer and Vanegas, '74a), H. rufus (Ito et al., '80), and C. auratus (Meek, '81a; and present study) share a common morphology with respect to size (300-600 $\AA$ ) and shape of synaptic vesicles, mitochondrial morphology, and synapse type. The retinal terminals in the optic tecta and superior colliculi of other vertebrates are morphologically similar to retinotectal terminals in teleosts, e.g., amphibians (Szekely et al., '73; Matsumoto and Scalia, '81), avians (Reperant et al., '81; Acheson et al., '80), and mammals (Lund, '69; Vrenson and De Groot, '77; Mize, '83). The one exception to this observation is the morphology of retinotectal terminals in the viper, Vipera aspis L. (Reperant et al., '81). These terminals show a departure in mitochondrial morphology-i.e., the mitochondria have dark rather than light matrices. The terminals, however, do show some typical characteristics of retinotectal and retinocollicular terminals including round and oval synaptic vesicles and mitochondria with irregular cristae and large intracristal spaces. Thus, these two mor- 
phological characteristics are present in all retinotectal and retinocollicular terminals so far studied. Why the mitochondrial morphology of retinotectal and retinocollicular terminals should have a unique morphology is not clear. Perhaps pale mitochondria do not represent the normal morphology of the mitochondria, and rather this morphology is due to fixation artifact.

Retinal terminals of teleosts are also similar in their synaptic connections within the SFGS. The majority of retinal postsynaptic elements are small dendritic profiles (Laufer and Vanegas, '74a; Ito et al., '80), but synapses with vesicle-containing profiles also have been reported (Ito et al., '80; Laufer and Vanegas, '74a; '80; Meek, '81a,b). There is disagreement, however, about the synaptic vesicle morphology in these profiles. In the case of $H$. rufus and $E$. plumieri the vesicles were pleomorphic (Ito et al., '80; Laufer and Vanegas, '74a), whereas Meek ('81a) reported round vesicles in $C$. auratus. Our conclusion that the vesicles of C. auratus are pleomorphic is based not only on visual inspection but also on measurements of the ellipticity index. All studies which have examined random sections through the SFGS neuropil have concluded that retinal synapses rarely, if ever, involved cell somata or proximal dendritic shafts (Laufer and Vanegas, '74a; Ito et al., '80; present study).

The percent of retinal terminals containing mitochondria reported in this paper for $C$. auratus $(19 \%$ of the SFGS terminal population) agrees well with the corresponding number for $H$. rufus (15\%) (Ito et al., ' 80 ). When our value was expanded by $43 \%$ to estimate total retinal terminal density (based on the proportion of nonmitochondria-containing labeled terminals in HRP studies), the resultant $27 \%$ was considerably higher than the $15 \%$ reported by Meek ('81b) for retinal terminal density in C. auratus. This discrepancy may be due to different methods of sampling the SFGS. Meek ('81b) selected retinal terminals that contacted Golgi-labeled cell somata and their large dendritic processes. The present study showed that retinal terminals in the SFGS primarily contact small dendritic profiles; therefore, the study by Meek ('81a) may not have included a large population of retinal terminals. The area of the SFGS analzyed also differed in the two studies. Meek sampled regions throughout the radial extent of the SFGS while this study sampled the superficial $60 \%$ of the SFGS. However, this does not account for the discrepancy since Meek found larger densities of retinal terminals in the deep half of the SFGS. Our estimate of the percent of total terminals in the SFGS derived from retina (27\%) was significantly lower than the $37 \%$ reported by Murray and Edwards ('82) in goldfish. This difference in the percent of retinal terminals may be due to regional differences in the tectum. In both studies central tectum was sampled but in the case of Murray's study the extreme DM region of the tectum was sampled while our study sampled DL tectum. The proportion of R:P terminals differed significantly in these two regions. Murray and Edwards found that approximately $98 \%$ of the terminals contained round synaptic vesicles and the remaining $2 \%$ pleomorphic synaptic vesicles. The present study found the proportion of R:P terminals to be $38 \%: 62 \%$. An earlier study by Meek (' 81 ) examining the same area of SFGS in goldfish supports our results; Meek estimated the ratio of R:P terminals to equal $40 \%: 60 \%$. Variability in the proportion of R:P terminals in different areas of the SFGS leaves open the possibility that the percent of retinal terminals may also show regional variability.

There is general agreement that the optic nerve projects to other laminae besides the SFGS in the teleost optic tectum. In the goldfish, a number of studies, including our own, have shown five retinal projection laminae (Neale et al., '72; Springer and Landreth, '77; Schmidt, '79; Springer and Gaffney, '81), and in both $E$. plumieri and $H$. rufus three have been reported (Vanegas and Ebbesson, '73; Campbell and Ebbesson, '69). The current study is the first, however, to show evidence of retinal synaptic terminals in laminae other than the SFGS. This finding was predicted by Schmidt ('79) from his current source density recordings which showed optic nerve synaptic activity in four laminae of the tectum-i.e., SO, SFGS, mid-SGC, and SAC. Our failure to observe retinal terminals in the SAC may indicate that this lamina contains an extremely low density of retinal terminals and the sample size in this study was not large enough to detect them.

\section{ACKNOWLEDGMENTS}

The authors wish to thank Drs. C. Stürmer and S.S. Easter for helpful discussion and advice on this project. We also thank Drs. P. Raymond, J. Norden, and S.S. Easter for their critical review of the manuscript. We thank A. Angel and C. Cook for technical and photographic assistance, and V.M. Henley and C. LaRose for typing the manuscript. This work was supported by PHS EY-00168, NIH traineeship 2T32EYO7022-06, and PHS 5429-16-19.

\section{LITERATURE CITED}

Acheson, D.W.K., S.K. Kemplay, and K.E. Webster (1980) Quantitative analysis of optic terminal profile distribution within the pigeon optic tectum. Neuroscience 5:1067-1084.

Adams, J.C. (1977) Technical considerations on the use of horseradish peroxidase as a neuronal marker. Neuroscience $2: 141-145$.

Airhart, M.J., and R.M. Kriebel (1980) A quantitative study of the synaptic organization of the retinotectal pathway of the goldfish, $C$. auratus. Anat. Rec. 196:6A (abstract).

Attardi, D.G., and R.W. Sperry (1963) Preferential selection of central pathways by regenerating optic fibers. Exp. Neurol. 7:46-64.

Campbell, C.B.G., and S.O.E. Ebbesson (1969) The optic system of a teleost: Holocentrus re-examined. Brain Behav. Evol. 2:415-430.

Edds, M.C. (1979) Specificity and plasticity of retinotectal connections. Neurosci. Res. Program Bull. 17:251-358.

Grafstein, B. (1967) Transport of protein by goldfish optic fibers. Science 157:196-198.

Gray, E.G. (1959) Axo-somatic and axo-dendritic synapses of the cerebral cortex: an electron microscopic study. J. Anat. 93:420-433.

Heimer, L., and A. Peters (1968) An electron microscopic study of a silver stain for degenerating boutons. Brain Res. 8:337-346.

Ingham, C.A., and F.H. Guldner (1981) Identification and morphometric evaluation of the synapses of the optic nerve afferents in the optic tectum of the Axolotl (A mbystoma mexicanum). Cell Tissue Res. 214:593611.

Ito, H. (1971) Fine structure of the carp optic tectum. J. Hirnforsch. 12:325354.

Ito, H., A.B. Butler, and S.O.E. Ebbesson (1980) An ultrastructural study of the normal synaptic organization of the optic tectum and the degenerating tectal afferents from retina, telencephalon and contralateral tectum in a teleost, Holocentrus rufus. J. Comp. Neurol. 191:639-659.

Jacobson, M., and R.M. Gaze (1965) Selection of appropriate tectal connections by regenerating optic nerve fibers in the adult goldfish. Exp. Neurol. 13:418-430.

Laufer, M., and H. Vanegas (1974a) The optic tectum of a perciform teleost. II. Fine structure. J. Comp. Neurol. 154:61-96. 
Laufer, M., and H. Vanegas (1974b) The optic tectum of a perciform teleost. III. Electron microscopy of degenerating retinotectal afferents. J. Comp. Neurol. 154:87-116.

Lund, R.D. (1969) Synaptic patterns of the superficial layers of the superior colliculus of the rat. J. Comp. Neurol. 135:179-208.

Marotte, L.R. (1981) Density of optic terminals in half tecta of goldfish with compressed retinotectal projections. Neuroscience 6:679-701.

Marotte, L.R., and R.F. Mark (1975) Uitrastructural localization of synaptic input to the optic lobe of carp (Carassius carassius). Exp. Neurol. 49:772789.

Matsumoto, D.E., and F. Scalia (1981) Long-term survival of centrally projecting axons in the optic nerve of the frog following destruction of the retina. J. Comp. Neurol. 202:126-135.

Meek, J. (1981a) A Golgi-electron microscopic study of goldfish optic tectum. I. Description of afferents, cell types, and synapses. J. Comp. Neurol. 199:149-174

Meek, J. (1981b) A Golgi-electron microscopic study of goldfish optic tectum. II. Quantitative aspects of synaptic organization. J. Comp. Neurol. 199:175-190.

Mize, R.R. (1983) Variations in the retinal synapses of the cat superior colliculus revealed using quantitative electron microscope autoradiography. Brain Res. 269:211-221.

Murray, M. (1976) Regeneration of retinal axons in the goldfish optic tec tum. J. Comp. Neurol. 168:175-196.

Murray, M., and M. Edwards (1982) A quantitative study of the goldfish optic tectum following optic nerve crush. J. Comp. Neurol. 209:363-373.
Neale, J.H., E.A. Neale, and B.W. Agranoff (1972) Radioautography of the optic tectum of the goldfish after intraocular injection of ${ }^{3} \mathrm{H}$ proline. Science 176:407-410.

Reperant, J., J. Peyrichoux, and J.P. Rio (1981) Fine structure of the superficial layers of the viper optic tectum. A golgi and electron microscopic study. J. Comp. Neurol. 199:393-418.

Robson, J.A., and C.A. Mason (1979) The synaptic organization of terminals traced from individual labeled retino-geniculate axons in the rat. Neuroscience 4:99-111.

Schmidt, J.T. (1979) The laminar organization of optic nerve fibers in the tectum of goldfish. Proc. R. Soc. Lond. [Biol.] 205:287-306.

Sharma, S.C. (1972) The retinal projections in the goldfish: An experimental study. Brain Res. 39:213-223.

Springer, A.D., and J.S. Gaffney (1981) Retinal projections in the goldfish: A study using cobaltous-lysine. J. Comp. Neurol. 203:401-424.

Springer, A.D., and G.E. Landreth (1977) Direct ipsilateral retinal projections in goldfish (Carassius auratu). Brain Res. 124:533-537.

Stürmer, C. (1981) Synaptic interconnection of normal and regenerated optic axons in goldfish tectum. Pflugers Arch. (Suppl.) 389:R29.

Szekely, G., G. Setalo, and G. Lazar (1973) Fine structure of the frog's optic tectum: Optic fiber termination layer. J. Hirnforsch. 14:189-225.

Vanegas, H., and S.O.E. Ebbesson (1973) Retinal projections in the perchlike teleost Eugerres plumieri. J. Comp. Neurol. 151:331-358.

Vrensen, G., and D. De Groot (1977) Quantitative aspects of the synaptic organization of the superior colliculus in control and dark-reared rabbits. Brain Res. 134:417-428. 